\title{
Transscleral diode laser cyclophotocoagulation for the treatment of refractory glaucoma secondary to inflammatory eye diseases
}

\author{
Torsten Schlote, Matthias Derse, Manfred Zierhut
}

\begin{abstract}
Background-Inflammatory glaucoma is still a diagnostic and therapeutic dilemma and surgical intervention is always associated with a high risk of failure or reactivation of the inflammatory disease. In this study we prospectively examined the value of transscleral diode laser cyclophotocoagulation (TDLC) for the treatment of refractory inflammatory glaucoma.

Methods-22 eyes of 20 consecutive patients with inflammatory, medically uncontrollable, glaucoma secondary to chronic uveitis/trabeculitis $(n=18)$, chemical injury $(n=2)$, episcleritis $(n=$ 1 ), and necrotising scleritis with inflammation ( $n=1)$ were treated by TDLC. Nine eyes $(41 \%)$ had had previous failed glaucoma surgery (trabeculectomy, cyclocryocoagulation) and 15 eyes (68.2\%) had had previous anterior segment surgery. All patients were followed for 1 year after the initial treatment.
\end{abstract}

Results-Within 12 months of the first treatment the intraocular pressure was controlled in $77.3 \%$ of all eyes $(72.2 \%$ of those with uveitic glaucoma). No serious side effects such as activation of the inflammatory process, phthisis bulbi or persistent hypotonia were observed, except one patient with a temporary fibrin reaction. More than one treatment was necessary in $63.6 \%$ of the patients. The use of systemic carbonic anhydrase inhibitors was reduced from $68.2 \%$ before treatment to $27.3 \%$ after 1 year.

Conclusion-TDLC seems to be a safe and effective procedure for the treatment of inflammatory glaucoma and may become an alternative to trabeculectomy with antimetabolites in uveitic glaucoma. TDLC may become the surgical procedure of choice in treating secondary glaucoma caused by chemical injury and also in scleritis associated glaucoma, using reduced parameters for application.

(Brf Ophthalmol 2000;84:999-1003)

Ophthalmology and Experimental Ophthalmic Surgery, University Eye

Hospital, Tuebingen, D-72076, Germany

T Schlote

M Derse

M Zierhut

Correspondence to: Dr T Schlote

Torsten.Schlote@

med.uni-tuebingen.de

Accepted 25 April 2000 drugs such as miotics, metipranolol, and latanoprost seem to be contraindicated, not effective, or have not yet been investigated. ${ }^{2}{ }^{3}$
Surgical intervention such as trabeculectomy or cyclocryotherapy is always associated with a high risk of failure or activation of the inflammatory disease. Further research is therefore needed on the therapeutic possibilities for inflammatory glaucoma.

Transscleral diode laser cyclophotocoagulation (TDLC) is a relatively new cyclodestructive procedure in the treatment of advanced refractory glaucoma. Although clinical experience is still limited, less severe side effects occur with this method than with cyclocryocoagulation or neodymium:YAG cyclophotocoagulation. ${ }^{4-6}$ Our own observations, as well as those reported in the literature, show that less inflammatory response is induced with cyclophotocoagulation than with cyclocryotherapy. Success rates of $38-85 \%$ have been reported with TDLC, regardless of the various differences between these studies. ${ }^{4-15}$ No large or prospective study has investigated the effectiveness and safety of TDLC in inflammatory glaucoma.

The purpose of this prospective study was to determine whether TDLC may be an effective, as well as safe, procedure for lowering intraocular pressure (IOP) in glaucoma caused by inflammatory ocular diseases.

\section{Patients and methods}

In January 1997 we initiated a prospective study to evaluate the effectiveness and safety of contact TDLC in cases of advanced glaucoma refractory to medical, surgical, or alternative treatments. Out of 100 consecutive patients, 20 patients (22 eyes) had inflammatory glaucoma without pupillary block and were mostly recruited from the outpatient service for inflammatory eye diseases at the University Eye Hospital, Tuebingen. Because information on the effectiveness of surgical procedures in inflammatory glaucoma is generally limited, we describe and discuss these patients separately.

All patients had inflammatory glaucoma which was uncontrolled despite maximum medical treatment. TDLC was performed if previous glaucoma surgery (trabeculectomy, cyclocryocoagulation) had failed, if there were additional risk factors for trabeculectomy (aphakia, pseudophakia), or if trabeculectomy and cyclocryocoagulation were associated with a very high risk of severe side effects (necrotising scleritis). All patients gave informed consent for cyclodiode treatment.

At our hospital subconjunctival anaesthesia was introduced as the standard procedure for TDLC in 1997. ${ }^{5}$ Oxybuprocaine, approximately 4-6 drops, was instilled in the eye and 
$2.5 \mathrm{ml} 2 \%$ mepivacaine was then placed beneath the conjunctiva. The needle was carefully placed $6-8 \mathrm{~mm}$ from the limbus to avoid bleeding at the injection site near the limbus. The eye was patched for 15 minutes with low pressure. No sedation by oral or intravenous medication was given. Only a 9 year old child and a woman with anterior necrotising scleritis with staphyloma formation were treated under general anaesthesia. The laser energy was delivered through a contact fibreoptic G probe (IRIS Endoprobe) attached to the Oculight SLx semiconductor diode laser (Iris Medical Instruments Inc, CA, USA).

Treatment was defined as successful if the IOP could be reduced to $5-21 \mathrm{~mm} \mathrm{Hg}$ with or without medication in all eyes with a visual acuity of at least 0.02 or more and in monocular patients. In eyes with a visual acuity of hand movements or less (including blind eyes) TDLC was performed to reduce a very high IOP to less than $30 \mathrm{~mm} \mathrm{Hg}$ and, additionally, to reduce pain and avoid further complications and enucleation. A further aim of the treatment was reduction of the use of systemic carbonic anhydrase inhibitors in all patients. Normal treatment consisted of 10-15 applications of $2.0 \mathrm{~W}$ energy applied for 2 seconds to treat not more than $270^{\circ}$ (not more than $180^{\circ}$ in patients with glaucoma secondary to chemical injury). The energy level and length of treatment were reduced in cases of thinned sclera such as necrotising scleritis and after the occurrence of pop effects.

After surgery $0.5 \mathrm{ml}$ dexamethasone was applied subconjunctivally. The patients received topical non-steroidal anti-inflammatory medication (diclofenac) five times a day (no cells or cells $1+$ in the anterior chamber) or topical corticosteroids (prednisolone acetate $1 \%$, cells $>1+$ ). Antiglaucomatous medication was continued and gradually withdrawn during the follow up period. At first, oral carbonic anhydrase inhibitors were withdrawn. If no adequate IOP response was obtained 6 weeks after the first treatment, patients underwent repeated TDLC for a maximum of four treatments.

Baseline information included age, race, sex, underlying inflammatory disease, visual acuity, IOP, medication, slit lamp biomicroscopic appearance, optic nerve head appearance, previous glaucoma, and other surgery.

Follow up examinations were performed on the first day and after 6 weeks, 3 months, 6 months, 9 months, and 12 months. After every TDLC the effect of treatment was monitored after 6 weeks. At each follow up examination the visual acuity, IOP, medication, slit lamp biomicroscopic appearance, and complications were recorded.

Statistical analysis was performed using the paired $t$ test to evaluate changes from baseline IOP and number of medications.

\section{Results}

Patient characteristics are shown in Table 1. Of the 22 eyes, nine $(40.9 \%)$ had previous failed glaucoma surgery (trabeculectomy, laser trabeculoplasty, cyclocryocoagulation) and 15
Table 1 Characteristics of patients and diagnosis

\begin{tabular}{ll}
\hline Number of patients (all white) & 20 \\
Number of eyes & 22 \\
Mean (SD) age (years) & $50.3(20.6)$ \\
range & $9-77$ \\
F:M & $13: 7$ \\
Underlying inflammatory eye diseases & \\
CAU of unknown aetiology & 5 \\
Herpes keratouveitis/trabeculitis & 6 \\
CAU associated with JCA & 3 \\
CAU in Cogan's syndrome & 2 \\
Intermediate uveitis of unknown aetiology & 1 \\
Panuveitis of unknown aetiology & 1 \\
Necrotising scleritis with inflammation & 1 \\
$\quad$ and uveitis & 1 \\
Episcleritis & 2 \\
Chemical injury & \\
Previous glaucoma surgery & 5 \\
Trabeculectomy & 5 \\
Cyclocryocoagulation & 2 \\
Laser trabeculoplasty & 2 \\
Previous other surgery & \\
Pseudophakic & 6 \\
Aphakic & 6 \\
Keratoplasty & 2 \\
$\quad$ cxcision of conjunctival tissue after & 1 \\
\hline CAU & \\
\hline
\end{tabular}
$\overline{\mathrm{CAU}}=$ chronic anterior uveitis, JCA $=$ juvenile chronic arthritis.

(68.2\%) had previous anterior segment surgery. In all patients the underlying inflammatory disease was controlled by antiinflammatory medication before TDLC was performed and remained the same postoperatively.

Only two patients were treated under general anaesthesia: a 60 year old woman with necrotising scleritis with inflammation and staphyloma formation (high risk of perforation) and a 9 year old girl with chronic anterior uveitis associated with juvenile chronic arthritis (JCA). In the remaining 18 patients sufficient anaesthesia was achieved by subconjunctival injection of mepivacaine $2 \%$. During the follow up of 12 months, 44 TDLCs (mean of two treatments per eye) were performed. Eight eyes received a single treatment, seven eyes received two treatments, six eyes received three treatments, and one eye received four treatments. Because no response was seen in the child with JCA associated uveitis and glaucoma, a cyclocryocoagulation was performed 9 months after the initial TDLC. The symptoms in the patient with necrotising scleritis with inflammation were controlled with methotrexate. Because of the circular scleral thinning with staphyloma formation, the total energy for TDLC was reduced to nearly one quarter (12 laser spots, 1 second, $1.25 \mathrm{~W})$. No activation of scleritis or uveitis was seen postoperatively and IOP was controlled.

The mean pretreatment IOP for all eyes (except the child with cyclocryocoagulation after 9 months) was 30.7 (SD7.3) $\mathrm{mm} \mathrm{Hg}$ and significantly decreased to 21.5 (7.8) $\mathrm{mm} \mathrm{Hg}$ after 6 weeks $(\mathrm{p}=0.0002), 21.98$ (7.6) $\mathrm{mm} \mathrm{Hg}$ after 3 months $(\mathrm{p}=0.0003)$, 18.7 (7.5) $\mathrm{mm} \mathrm{Hg}$ after 6 months $(\mathrm{p}<0.0001)$, 17.8 (7.6) $\mathrm{mm} \mathrm{Hg}$ after 9 months $(\mathrm{p}<0.0001)$, and to $19.4(8.9) \mathrm{mm} \mathrm{Hg}$ at 12 months $(p<0.0001)$. Successful lowering of IOP as defined above was achieved in 17 eyes $(77.3 \%)$. The use of systemic carbonic anhydrase inhibitors was reduced from $68.2 \%$ before treatment to $27.3 \%$ after 1 year. The 
Table 2 Complications after TDLC in 22 eyes with inflammatory glaucoma

\begin{tabular}{ll}
\hline Complications/side effects & No of eyes (\%) \\
\hline During CPC & $2(9)$ \\
$\quad$ Pop effects & $1(4.5)$ \\
Conjunctival burns & $12(54.5)$ \\
First day postoperatively & $1(4.5)$ \\
Cells and flare & $1(4.5)$ \\
Fibrin clot & $8(38.1)$ \\
Erosio corneae & 0 \\
Within 12 months after first CPC & 0 \\
Decreased visual acuity & \\
Hypotonia (<5 mm Hg) & \\
Phthisis &
\end{tabular}

$\mathrm{CPC}=$ cyclophotocoagulation.

Table 3 Visual acuity before cyclophotocoagulation $(n=$ 22) and after 1 year $(n=21)$ of follow up

\begin{tabular}{lll}
\hline Visual acuity & Preoperatively & After 1 year \\
\hline $20 / 16-20 / 20$ & 2 & 3 \\
$20 / 25-20 / 32$ & 4 & 2 \\
$20 / 40-20 / 50$ & 2 & 2 \\
$20 / 63-20 / 100$ & 2 & 3 \\
$20 / 400-20 / 200$ & 5 & 5 \\
HM & 4 & 2 \\
LP & 1 & 3 \\
NLP & 1 & 1
\end{tabular}

$\mathrm{NLP}=$ no light perception, $\mathrm{LP}=$ light perception, $\mathrm{HM}=$ hand movements.

The 9 year old child with JCA received cyclocryocoagulation 9 months after initial TDLC and was excluded.The decrease in visual acuity in eight patients was caused by cataract progression in two eyes, increased corneal opacification in two, and glaucoma progression in four eyes.

average number of topical antiglaucomatous drugs used was 2.55 (1.5) before surgery and 2.0 (1.2) after 12 months follow up ( $p=0.08$ ).

The procedure failed in five eyes with uveitic glaucoma so the success rate in 18 eyes with uveitic glaucoma was $72.2 \%$. Fifteen cyclophotocoagulations were performed in these five eyes. Two of the five eyes were aphakic; three had previous failed cyclocryocoagulation (including the child with JCA associated uveitis) and two a previous failed trabeculectomy.

In all 22 eyes no serious complications occurred during the 12 months following the initial treatment (Table 2). Nearly half of the patients had mild anterior uveitis on the first postoperative day. Only one female patient with secondary glaucoma after herpes keratouveitis and perforating keratoplasty had a fibrin reaction in the anterior chamber. Using subconjunctival dexamethasone and topical prednisolone acetate, the fibrin reaction disappeared after three days. No reactivation of the underlying inflammatory disease was seen.

Visual acuity remained the same in eight eyes $(38.1 \%)$, improved in five $(23.8 \%)$, and decreased in eight eyes (38.1\%) (Table 3$)$. The decrease in visual acuity in eight patients was caused by cataract progression in two eyes, increased corneal opacification/scarring in two (chemical injury, keratouveitis), and progression of glaucomatous optic neuropathy in four eyes.

\section{Discussion}

The results of our study indicate that TDLC can be successfully performed with a low risk for complications in inflammatory glaucoma. There were no cases of phthisis, hypotonia, or marked activation of the underlying inflamma- tory disease except in one patient with a fibrin reaction. The overall success rate of $77.3 \%$ is comparable to that found in other studies on the use of TDLC in patients with heterogeneous glaucoma. ${ }^{4-15}$ However, in contrast to other studies, we found that repeated treatments were often necessary $(63.6 \%)$.

In this study TDLC was successful in $72.2 \%$ of 18 eyes with uveitic glaucoma. Our results are in accordance with the recently published analysis by Spencer and Vernon ${ }^{7}$ who reported on nine eyes with uveitic glaucoma out of 58 eyes with different types of glaucoma. Their results were comparable to other types of glaucoma (aphakic glaucoma, primary open angle glaucoma) and no phthisis or marked activation of the underlying inflammatory disease was observed. In the largest study on the treatment of refractory glaucoma by TDLC, nine out of 210 eyes had uveitic glaucoma. ${ }^{6}$ The inflammatory reaction after treatment did not differ from that found in other types of glaucoma. Similar findings were also reported by Brancato et $a l^{4}{ }^{4}$ although they found that TDLC was successful in only two of five eyes. Several reports on non-contact neodymium:YAG laser cyclophotocoagulation include a limited number of eyes with uveitic glaucoma and also report a good outcome with no increase in complications compared with those found with other types of glaucoma. ${ }^{16-18}$

The results obtained with TDLC have to be discussed in comparison with other surgical procedures such as trabeculectomy, Molteno implantation, and cyclocryocoagulation. It is known that trabeculectomy in patients with uveitis or previous surgery is associated with a relatively high risk of failure. ${ }^{19}$ Using antimetabolites, the results of trabeculectomy improved, although a significant risk of side effects (bleb related side effects such as prolonged hypotonia and corneal toxicity) exists. $^{20}$ In uveitic glaucoma trabeculectomy with 5-fluorouracil (5-FU) was successfully performed in $65-85 \%$ of eyes. ${ }^{21-23}$ However, Patitsas et $a l^{4}$ found a high risk of cataract progression (90\%) and failure in aphakic and pseudophakic eyes (45\%) after trabeculectomy with 5-FU in uveitic glaucoma.

Bearing in mind that most of our patients had had previous anterior segment surgery, which is an additional risk factor for trabeculectomy, TDLC may become a comparable alternative to filtration surgery with antimetabolites. However, further information is needed about the long term outcome of TDLC in uveitic glaucoma as well as a direct comparison with trabeculectomy.

Molteno implantation may be another effective procedure but is associated with a relatively high incidence of complications (hyphaema, Tenon cyst formation, phthisis, choroidal effusion, and severe postoperative uveitis)..$^{2526}$ Surprisingly good results were reported by Hill et $a l^{27}$ who compared trabeculectomy without antimetabolites with Molteno implantation in patients with inflammatory glaucoma and found a 1 year and 2 year life table success rate of $81 \%$ and $73 \%$ for trabeculectomy and $79 \%$ and $79 \%$ for Molteno 
implantation. Välimäki et $a l^{28}$ evaluated the outcome of Molteno implantation in secondary glaucoma associated with JCA associated uveitis and achieved a successful outcome in $89 \%$ of eyes (mean follow up 40 months). However, intraoperative complications were seen in $26 \%$ of the patients and postoperative complications in $30 \%$.

The high complication rate (phthisis, macular oedema, severe prolonged uveitis) associated with cyclocryotherapy with all types of glaucoma limits its use to the surgical procedure of last choice. ${ }^{29}{ }^{30}$ Little is known about the efficacy and risks in inflammatory glaucoma. Some authors observed no increased rate of severe complications compared with other types of glaucoma. ${ }^{3132}$ However, in a study of three eyes with inflammatory glaucoma and previous intraocular surgery treated with cyclocryocoagulation, Wesley and Kielar ${ }^{33}$ reported that all three eyes developed hypotonia postoperatively. TDLC acts selectively by melanin absorption and therefore the inflammatory reaction may be less intense than with cyclocryotherapy. Because the incidence of severe complications is lower with TDLC, it should be preferred.

Scleritis associated and episcleritis associated glaucoma are rare secondary glaucomas. Only single reports can be found regarding the successful use of trabeculectomy. ${ }^{3435}$ Because filtering surgery in scleritis may be associated with an increased risk of sclera melting and because scleritis itself is a potentially destructive disease, the adjuvant use of antimetabolites seems to be contraindicated. Cyclocryotherapy in scleritis may result in a marked activation of the inflammatory process and may additionally result in perforation or further scleral atrophy and thinning. Cyclocryotherapy should therefore only be performed if all other medical and surgical interventions (including cyclophotocoagulation) have failed to reduce the high IOP. In contrast, the normal sclera is usually not affected by cyclophotocoagulation. ${ }^{4}$ Only one case of perforation in an area of thinned sclera has been reported after TDLC with normal parameters ( $1.75 \mathrm{~W}, 2$ seconds). ${ }^{8}$ Using TDLC we successfully treated a patient with necrotising scleritis with staphyloma formation and secondary glaucoma. Because the need for energy adjustment in eyes with abnormal scleral thinning has been demonstrated experimentally, we reduced the applied total energy to nearly one quarter. ${ }^{36}$

Information on the surgical management of secondary glaucoma resulting from severe chemical injury is also limited. Trabeculectomy has been successfully performed in a few cases in which the conjunctiva was less affected. ${ }^{37}$ Nothing is known about the use of antimetabolites. The risk of cornea, sclera, and bleb related complications may be markedly increased and antimetabolites are therefore probably contraindicated. Cyclocryotherapy may induce a severe inflammatory response and cause further damage to the sclera. It remains the procedure of last choice. In 1988 Zaidman and Wandel ${ }^{38}$ were the first to treat successfully an eye with uncontrollable glau- coma after a severe alkali burn without complications using non-contact transscleral neodymium:YAG cyclophotocoagulation. We successfully treated two eyes with severe glaucoma after chemical injury by TDLC over $180^{\circ}$. No serious side effects occurred. Because usually no further scleral or conjunctival damage will be induced by TDLC, it should be preferred to cyclocryotherapy.

In conclusion, TDLC seems to be a safe and effective procedure for the treatment of inflammatory glaucoma. In uveitic glaucoma a direct comparison of TDLC and trabeculectomy with antimetabolites is needed. TDLC may become the surgical procedure of choice in treating secondary glaucoma resulting from chemical injury and also in scleritis associated glaucoma (using reduced parameters for application), because the risk of complications is probably lower than with other procedures. Nevertheless, further information is required, especially on the long term effects of TDLC.

The authors thank Dr A Kurtenbach from the University Eye Hospital, Tuebingen for her critical review of our manuscript.

1 Schlote T, Zierhut M. Ocular hypertension and glaucoma associated with scleritis and uveitis. Aspects of epidemiology, pathogenesis and therapy. Dev Ophthalmol 1999;30:91-109.

2 Melles RB, Wong IG. Metipranolol-associated granulomatous iritis. Am f Ophthalmol 1994;118:712-5.

3 Warwar RE, Bullock JD, Ballal D. Cystoid macular edema and anterior uveitis associated with latanoprost use. Ophthalmology 1998;105:263-8.

4 Brancato R, Carassa RG, Bettini P, et al. Contact transscleral cyclophotocoagulation with diode laser in refractory glaucoma. Eur $\mathcal{F}$ Ophthalmol 1995;5:32-9.

5 Schlote T, Kreutzer B, Kriegerowski M, et al. DiodenlaserZyklophotokoagulation in der Behandlung therapierefrakZyklophotokoagulation in der Behandlung therapierefrak6 tärer

6 Bloom PA, Tsai JC, Sharma K, et al. "Cyclodiode" transscleral diode laser cyclophotocoagulation in the treatment of advanced refractory glaucoma. Ophthalmology 1997;104:1508-20.

7 Spencer AF, Vernon SA. "Cyclodiode": results of a standard protocol. Br f Ophthalmol 1999;83:311-6.

8 Gaasterland DE, Pollack IP. Initial experience with a new method of laser transscleral cyclophotocoagulation for ciliary ablation in severe glaucoma. Trans Am Ophthalmol Soc 1992; LXXXX:225-46.

9 Youn J, Cox TA, Herndon LW, et al. A clinical comparison of transscleral cyclophotocoagulation with neodymium: YAG and semiconductor diode lasers. Am $\mathcal{f}$ Ophthalmol 1998;126:640-7.

10 Bock CJ, Freedman SF, Buckley EG, et al. Transscleral diode laser cyclophotoocagulation for refractory pediatric glaucoma. F Pediatr Ophthalmol Strabismus 1997;34:235-9.

11 Kosovo O, Gaasterland DE, Pollack IP, Enger CL, the Diode Laser Ciliary Ablation Study Group. Long-term outcome of initial ciliary ablation with contact diode laser transscleral cyclophotocoagulation for severe glaucoma. Ophthalmology 1996;103:1294-302.

12 Wong EYM, Chew PTK, Chee CKL, et al. Diode laser contact transscleral cyclophotocoagulation for refractory glaucoma in Asian patients. Am f Ophthalmol 1997;124:797804.

13 Werner A, Vick H-P, Guthoff R. Zyklophotokoagulation mit dem Diodenlaser. Ophthalmologe 1998;95:176-80.

14 Ulbig MW, McHugh DA, McNaught AI, et al. Clinical comparison of semiconductor diode versus neodymium: Comparison of semiconductor diode versus neodymium: YAG non-contact

15 Threlkeld AB, Johnson MH. Contact transscleral diode cyclophotocoagulation for refractory glaucoma. I Glaucoma 1999;8:3-7.

16 Youn J, Cox TA, Allingham RR, et al. Factors associated with visual aciuty loss after noncontact transscleral Nd:YAG cyclophotocoagulation. F Glaucoma 1996;5:3904.

17 Shields MB, Shields SE. Nonconatct transscleral Nd:YAG cyclophotocoagulation: a long-term follow-up of 500 patients. Trans Am Ophthalmol Soc 1994;XCII:271-87.

18 Barraquer RI, Kargacin M. Nd:YAG laser diascleral cyclophotocoagulation: Survival analysis after four years. Dev Ophthalmol 1991;22:132-7.

19 Veldman E, Greve EL. Glaucoma filtering surgery, a retrospective study of 300 operations. Doc Ophthalmol 1987;67:151-70. 
20 Ticho U, Ophir A. Late complications after glaucoma filtering surgery with adjunctive 5-fluorouracil. Am $\mathcal{F}$ Ophthal-

21 Weinreb RN. Adjusting the dose of 5-fluorouracil after filtration surgery to minimize side effects. Ophthalmology 1987;94:564-70.

22 Jampel HD, Jabs DA, Quigley HA. Trabeculectomy with 5-fluorouracil for adult inflammatory glaucoma. $A m \mathcal{F}$ Ophthalmol 1990;109:168-73.

23 Cheung JC, Wright MM, Murali S, et al. Intermediate-term outcome of variable dose mitomycin C filtering surgery. Ophthalmology 1997;104:143-9.

24 Patitsas CJ, Rockwood EJ, Meisler DM, et al. Glaucoma filtering surgery with postoperative 5 -fluorouracil in patients with intraocular inflammatory disease. Ophthalmology 1992;99:594-9.

25 Freedman J, Rubin B. Molteno implantation as a treatment for refractory glaucoma in black patients. Arch Ophthalmol $1417-20$.

26 Melamed S, Cahane M, Gutman I, et al. Postoperative complications after Molteno implant surgery. Am $\mathcal{F}$ Ophthalmol 1991;111:319-22.

27 Hill RA, Nguyen QH, Baerveldt G, et al. Trabeculectomy and molteno implantation for glaucomas associated with uveitis. Ophthalmology 1993;100:903-8.

28 Välimäki J, Airaksinen J, Tuulonen A. Molteno implantation for secondary glaucoma in juvenile rheumatoid arthritis. Arch Ophthalmol 1997;115:1253-6.

29 Brindley G, Shields MB. Value and limitations of cyclocryo-
30 Benson MT, Nelson ME. Cyclocryotherapy: a review of cases over a ten-year period. Br f Ophthalmol 1990;74:1035 .

31 Nicaeus Th, Derse M, Schlote T, et al. Die Zyklokryokoagulation in der Behandlung therapierefraktärer Glaukome: Eine retrospektive Analyse von 185 Zyklokryokoagulationen. Klin Monatsbl Augenheilkd 1999;214:224-30.

32 Klein J, Küchle HJ. Ergebnisse der Kryoanämisation des Ziliarkörpers bei prognostisch ungünstigen Sekundärglaukomen. Klin Monatsbl Augenheilkd 1981;178:470-2.

33 Wesley RE, Kielar RA. Cyclocryotherapy in treatment of glaucoma. Glaucoma 1980;3:533-8.

34 McGavin DDM, Williamson J, Forrester JV, et al. Episcleritis and scleritis. A study of their clinical manifestations and association with rheumatoid arthritis. $\mathrm{Br} \mathcal{F}$ Ophthalmol 1976;60:192-226.

35 Wilhelmus KR, Grierson I, Watson PG. Histopathologic and clinical associations of scleritis and glaucoma. Am $\mathcal{f}$ Ophthalmol 1981;91:697-705.

36 Palmer DJ, Cohen J, Torczynski E, et al. Transscleral diode laser cyclophotocoagulation on autopsy eyes with abnor-
mally thinned sclera. Ophthalmic Surg Lasers 1997;28:495500 .

37 Kuckelkorn R, Kottek A, Reim M. Intraokulare Komplikationen nach schweren Verätzungen-Häufigkeit und chirurgische Behandlung. Klin Monatsbl Augenheilkd 1994;205: 86-92.

38 Zaidman GW, Wandel T. Transscleral YAG laser cyclopho-
tocoagulation for uncontrollable glaucoma in corneal patients. Cornea 1988;7:112-4. 